\title{
Predicting interpersonal attraction toward strangers presented in three different stimulus modes'
}

DONN BYRNE AND GERALO L. CLORE, JR. UNIVERSITY OF TEXAS

Attraction toward a stranger is a positive linear function of the proportion of his responses to an attitude scale which are similar to those of the $S$. Though various experimenters have utilized different stimulus modes for presenting the stranger, the effects of such stimulus differences have not been systematically compared nor has the linear function been demonstrated to be generalized across conditions. Ss were assigned to one of three experimental conditions in which a stranger was either depicted in a sound $8 \mathrm{~mm}$ color movie, recorded on tape, or represented by responses on a mimeographed attitude scale. After learning 12 of the stranger's opinions, $S_{S}$ were asked to evaluate him. In all three stimulus modes, attraction was found to be a function of proportion of similar attitudes, with no significant differences attributable to conditions. A straight-line function was fitted to the data, yielding the formula $Y=6.74 X+5.06$. This finding adds to the generality of the attitude-attraction relationship and also provides a methodological improvement.

With data obtained in relatively specific stimulus conditions, Byrne \& Nelson (1965) found that attraction toward a stranger is a positive linear function of the proportion of his responses on an attitude scale which are similar to those of the $\mathrm{S}$. These data were drawn from studies employing a total of 790 Ss who had examined an attitude scale purportedly filled out by a stranger. It was proposed that this linear function is a general one, but the possibility remained that it is dependent on that specific method of presenting the stimulus person.

In other experimental investigations of interpersonal attraction, the stimulus person utilized to elicitattraction responses has been presented in a variety of ways. For example, Ss have been asked to respond to another individual who is actually a stooge (Aronson \& Linder, 1965), who is depicted in a specially prepared motion picture (Altrocchi, 1959), whose photograph is shown to the S (Byrne \& McGraw, 1964), and whose voice has been recorded on tape (Jones, 1965). The possible influence of mode of presentation on attraction has not been investigated. It is possible, for example, that as the number of available cues (e.g., voice quality, attractiveness, accent) increases, the prediction of attraction on the basis of attitude similarity becomes progressively less accurate.

In the present investigation, the generality of the relationship between attitude similarity and attraction across stimulus modes is determined. Specifically, the functional relationship between proportion of similar attitudes and attraction is examined under three different conditions of stimulus presentation: a color movie with sound track, a tape recording, and written responses on a mimeographed attitude scale.

Method

The Ss consisted of 120 introductory psychology students (60 males, 60 females) at the University of Texas. Each was randomly assigned to one of three experimental conditions in which small groups of Ss were asked to fill out a 12-item Survey of Attitudes dealing with such varied topics as racial integration, political parties, and classical music. Afterward, the Ss were told that the experiment dealt with the accuracy of interpersonal judgments. They would be given the opportunity to learn something about another undergraduate student and then would be asked to make judgments about that person's intelligence, knowledge of current events, morality, and adjustment and also to indicate how much they believed they would like the person and how much they would like to work with him or her. The latter two items, each consisting of a seven-point scale, are added to provide the measure of the dependent variable which ranges from 2 to 14 points (Byrne \& Nelson, 1965).

In each experimental condition, the "stranger" (the same sex as the $S$ ) responded with one of two standard patterns of attitude responses in order to control for the possible effects of specific content. In the movie condition, one male and one female each made two sound $8 \mathrm{~mm}$ color movies (A and B patterns) in which they expressed their opinions on each of the 12 topics. In the tape recording condition, the assistants each made two recordings identical to the movie sound tracks. In the mimeograph condition, faked attitude scale responses were devised following either pattern A or B.

Resulis

The similarity between any given $S$ and the stranger to whom he was exposed could vary from 0 to 12 (.00 to 1.00 similar attitudes); in the present sample the actual variation was from 1 to 10 (.08 to .83 similar attitudes). A three by four factorial analysis of variance was carried out. Attitude similarity was found to have a highly significant effect on attraction $(F=11.20$, df $=3 / 108, p<.001$ ), but neither the effect of the three stimulus modes nor of the interaction were statistically significant.

Combining the data for all $120 \mathrm{Ss}$, the relationship between proportion of similar attitudes and attraction was plotted as shown in Fig. 1. A straight-line function 


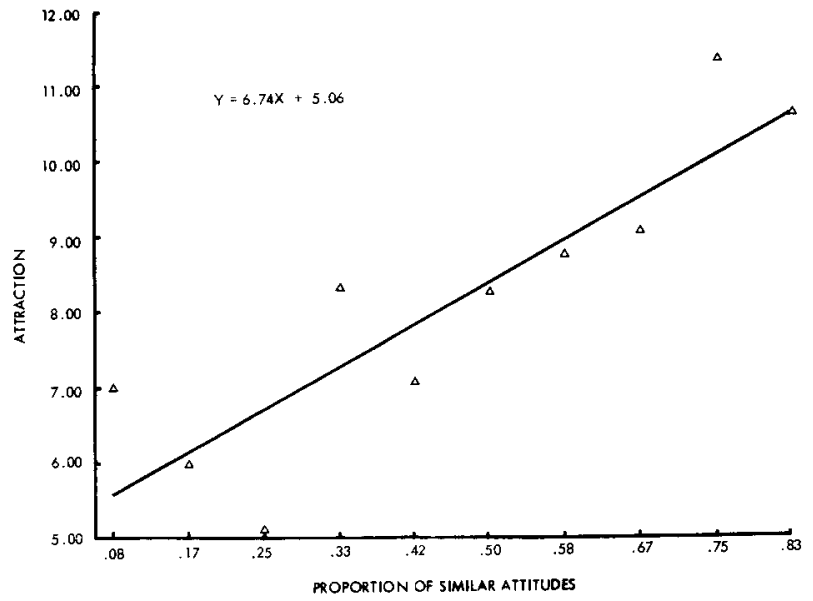

Fig. 1. Attraction toward a stranger as a linear function of proportion of similar attitudes with movie, tape recording, and mimeograph conditions combined.

was fitted to the data by the least squares method; the solution yielded the formula $\mathrm{Y}=6.74 \mathrm{X}+5.06$. Thus, the linear relationship between attitude similarity and attraction is once again found even though the mode of stimulus presentation is altered.

It should be noted that the specific $m$ and $k$ values for the present data differ from those reported by Byrne and Nelson $(Y=5.44 X+6.62)$. By a goodness of fit analysis, a significant difference was found between the Byrne-Nelson line and the present data ( $E=4.09$, df $=10 / 110, p<.01$ ). Specifically, the linear function depicted in Fig. 1 has greater slope and a lower $Y$ intercept than the previously reported one. It is possible that these differences are a function of the much shorter time period between response to the attitude scale and response to the stranger in the present design.

\section{Discussion}

The law of attraction (Byrne \& Nelson, 1965) states that attraction toward $\mathrm{X}$ is a positive linear function of the proportion of positive reinforcements received from $\mathrm{X}$; similar and dissimilar attitude statements are interpreted simply as special instances of positive and negative reinforcement (Golightly \& Byrne, 1964). This linear function has now been found to hold not only with respect to attitude similarity but for similar and dissimilar economic status (Byrne, Clore, \& Worchel, in press), responses to items of fact concerning both past and future events (Byrne, Nelson, \& Reeves, in press), evaluative statements concerning the subject (Byrne \& Rhamey, 1965), ratings of the originality of the subject's creative productions (McDonald, 1962), and responses given by the experimenter in a learning situation (Golightly, 1965).

Further, it appears that the effect of attitude similarity on attraction is not limited to any specific method of presenting the stimulus person. It should also be noted that methodologically, the present research design makes it easier to investigate the effects of other variables on the relationship between similarity and attraction. Rather than a two-step procedure in which a bogus stranger is laboriously constructed for each subject, attraction may be investigated in a single setting with "standard strangers."

\section{References}

Altrocchi, J. Dominance as a factor in interpersonal choice and perception. J. abnorm. soc. Psychol., 1959, 59, 303-308.

Aronson, E. \& Linder, D. Gain and loss of esteem as determinants of interpersonal attractiveness. J. exp. soc. Psychol., 1965, 1, 156-171.

Byme, D., Clore, G. L., Jr., \& Worchel, P. The effect of economic similarity-dissimilarity on interpersonal attraction. $J$. pers. soc. Psychol., in press.

Byme, D., \& McGraw, C. Interpersonal attraction toward Negroes. Hum. Relat., 1964, 17, 201-213.

Byrne, D., \& Nelson, D. Attraction as a linear function of proportion of positive reinforcements. $J$. pers. soc. Psychol., 1965, 1, 659-663.

Byme, D., Nelson, D., \& Reeves, K. Effects of consensual validation and invalidation on attraction as a function of verifiability. J. exp. soc. Psychol., in press.

Byrne, D., \& Rhamey, R. Magnitude of positive and negative reinforcement as a determinant of attraction. J. pers. soc. Psychol., 1965, 2, 884-889.

Golightly, Carole. The reinforcement properties of attitude similar ity-dissimilarity. Unpublished doctoral dissertation, University of Texas, 1965.

Golightly, Carole, \& Byrne, D. Attitude statements as positive and negative reinforcements. Science, 1964, 146, 798-799.

Jones, E. E. Conformity as a tactic of ingratiation. Science, 1965. $149,144-150$.

McDonald, R. D. The effect of reward-punishment and affiliation need on interpersonal attraction. Unpublished doctoral dissertation, University of Texas, 1962.

\section{Note}

1. This research was supported by Research Grant MH-11178-01 from the National Institute of Mental Health, United States Public Health Service. The authors wish to thank Mrs. Lynn Godbout for her assistance. 